\title{
EL SUFRIMIENTO COLECIIVO DE UNA CIUDAD MINERA EN DECLINACIÓN. EL CASO DE LOTA, CHILE
}

\author{
Sonia E. Reyes Herrera \\ Juan Carlos Rodríguez Torrent \\ Universidad de Valparaíso - Chile \\ Patricio Medina Hernández \\ Universidad Católica de Valparaíso - Chile
}

Resumen: Lota, la primera ciudad industrial de Chile, monoproductora e identificada por 150 años con el carbón, se encuentra en un proceso irreversible de declinación simbólica y material. Marcada su historia por luchas contra la pobreza, la injusticia social y la demanda por derechos laborales, impulsadas por los sindicatos y el Partido Comunista, que estructuraron sus utopías sociales y urbanas, hoy se encuentra sumida en la derrota y el sufrimiento producido por una acumulación de eventos adversos en los últimos 40 años. La dictadura militar, el fin de los socialismos reales, la devaluación de los partidos políticos y el sindicalismo y el cierre de la mina, ponen fin a una cultura laboral y a un proyecto de ciudad que obliga a los extrabajadores y a sus habitantes a un proceso de reescritura biográfica que modifica su relación con el pasado y el futuro. En este artículo se realiza un análisis de las transformaciones productivas, sociales, políticas, culturales y arquitectónicas que muestran la emoción de una ciudad y la vida colectiva sumida en el dolor. Metodológicamente se desarrolla en base a un trabajo etnográfico sustentado en entrevistas a exmineros, mujeres, funcionarios públicos y revisión de fuentes de información secundaria, provenientes de registros históricos y literarios.

Palabras clave: ciudad minera, cultura del trabajo, sufrimiento, utopía.

* Este trabajo es producto del proyecto DIUV 67/2011 de la Universidad de Valparaíso-Chile, titulado: Esperanza y movilización social en Lota: Iglesias, partidos y sindicatos. Análisis de las relaciones entre política y religión en un contexto de transformaciones productivas, sociopolíticas y culturales.

Horizontes Antropológicos, Porto Alegre, ano 20, n. 42, p. 237-264, jul./dez. 2014 http://dx.doi.org/10.1590/S0104-71832014000200010 


\begin{abstract}
After 150 years of coal mining and industrial production, the southern Chilean town of Lota entered during the 70's a twofold process of continuous symbolic and material decline. Under the guidance of trade-unions and the Comunist Party, which provided the ideological basis that shaped the miners striving, the city's population is renowned for its struggle against poverty and social injustice. The declining process, still underway after 40 years, has been taken over by adversity ever since the closure of the coal mines, namely: the military dictatorship that devastated the country during twenty years; the demise of most socialist regimes that sustained the miners quest for social justice; the enfeeblement of both the political parties and trade unions, among other events, have undermined social determination, forcing a redrafting of the relationship with both past and future. Through an ethnographic approach, based on interviews with former miners, women and local authorities, together with a thorough review of secondary sources, this article examines the productive, social, political, cultural and architectural transformations that speak for a town immersed in pain and longing for a redefined social utopia.
\end{abstract}

Keywords: labor culture, mining town, suffering, utopia.

\title{
Introducción
}

En este artículo, una perspectiva del dolor y el sufrimiento no se ubica solo en el cuerpo, sino principalmente en el decaimiento y declinación de una ciudad que atraviesa el espacio público y privado, cuyo proceso - a veces más o menos acelerado- afecta a los volúmenes de la arquitectura, a la vida y la actividad ritual que le da sentido. Se entiende que "ataca al hombre en su identidad y a veces lo quiebra" (Le Breton, 1999, p. 15); que "todo dolor, incluso el más modesto, induce a la metamorfosis, proyecta a una dimensión inédita de la existencia, abre en el hombre una metafísica que trastoca su ordinaria relación con el prójimo y con el mundo" (Le Breton, 1999, p. 26).

El dolor no es un problema del hombre con su cuerpo, lo es del hombre con su mundo circundante. En el caso de los extrabajadores analizados en este artículo, a partir de los cambios políticos, económicos y urbanos en Lota (Chile), la ciudad del carbón y cuna del sindicalismo y de la clase obrera, se dimensiona como la imposibilidad de armar una relación con el futuro, ya que "caen", se "desenganchan" y se "desafilian" de los elementos cotidianos vinculantes (Castel, 2004, p. 58); se vuelven superfluos, no encajan en el modelo de convivencia (de país estelar) y sólo pueden elegir lo que se les

Horizontes Antropológicos, Porto Alegre, ano 20, n. 42, p. 237-264, jul./dez. 2014 
presenta por delante (Bauman, 2008). Ellos, experimentan un importante excedente de tiempo disponible, que supera al tiempo posible de trabajo (Gorz, 1995, p. 14-15); los abruma la soledad, la devaluación de su épica y falta de reconocimiento, la desafección política, laboral y generacional, marcados en el presente por la lucha contra la insignificancia de la vida. "El desocupado de larga duración se asfixia bajo el peso de una vida absolutamente privada" (Castel, 2004, p. 57), que se desgaja como la ciudad misma, que requiere dar "sentido" y "destino" al tiempo liberado. La vida laboral degradada hace que ésta quede atrapada por el asistencialismo de pensiones estatales, ya que "no pueden subvenir a sus necesidades básicas porque no están en condiciones de trabajar" (Castel, 1997, p. 29).

En Chile, país minero, esta situación ha configurado un largo cementerio de ciudades ruinas y culturas del trabajo que han debido modificar sus estrategias de sobrevivencia, a veces de manera simbólica y/o violentamente. Han sido expulsadas de sus territorios y de las relaciones cotidianas con los volúmenes propios de la actividad extractiva, las acciones y formas de sociabilidad. La declinación de estas ciudades (del cobre, salitre y de los ciclos de la plata, Garcés, $1999,2007)$ producto de la dependencia del recurso, hace en extremo vulnerable el territorio y la conformación de las urbes monodependientes, por lo que los cambios en la estructura de la demanda del producto transforma en víctima de los ciclos mineros a su población, impidiéndoles, la mayoría de las veces, biográficamente reinventarse, y a las ciudades reconvertirse o refundarse por la gran especialización que adquieren en su ligazón con las culturas del trabajo.

La figura que aparece a los investigadores, es que cada hombre y cada mujer que ve apagarse su ciudad, sienten que esta desvanece y decolora. También su modo de apropiarse con el mundo que ha ayudado a construir con sus acciones, los obliga en sus letanías a reconciliarse con su propia biografía: pasa desde un referente de identidad positivo a uno negativo. Y, este paso no es de fácil resolución. En este proceso, el dolor "no olvida a nadie y llama al orden de muy diversas maneras en el trascurso de la existencia" (Le Breton, 1999, p. 17).

Todo el sufrir en las ciudades mineras en declinación, y en Lota en particular, se asocia a una minimización de la vida y a una pérdida del valor de la experiencia laboral, a la incapacidad para poder movilizar recursos, estrategias, formas de defensa y de reposicionamiento y de reescritura de la propia vida. El sufrimiento es una manifestación de una amenaza y una encarnación del deterioro de la identidad. Implica una pérdida de las expectativas 
estructuradas como grupo frente a las cuales todos los miembros adquieren un sentido colectivo; confianza, reconocimiento de los méritos, demandas de compromiso frente a las acciones que armonizan los mandatos interiorizados y las expectativas externas. Ambas organizan las utopías del colectivo, como clase y cultura del trabajo.

Los modos singulares y reiterados del trabajo van definiendo el cotidiano, integrándose como un importante abanico de sistemas: parentales, vecinales, recreativos, comerciales, sanitarios, religiosos, entre otros. En la cultura chilena del carbón, existen dos espacios de sociabilidad masculina que se encuentran siempre unidos: el referido al trabajo bajo el océano y el recreativo-deportivo y de las cantinas.

Más allá de la ciudad de Lota, en perspectiva diacrónica se observa un sino común a las urbes mineras: tienen un ciclo de vida; nacen, se desarrollan y mueren. Y los sistemas y los proyectos vitales de sus habitantes no son ajenos a estas vicisitudes por la masculinización del trabajo, las especializaciones de sus integrantes, el repertorio limitado de roles a desempeñar y a su gran dependencia del exterior (valor y ley del mineral, costes de producción y tecnología). Así, todo cambio en la explotación y trabajo, por nimio que sea, afecta la estabilidad de la vida y la relación con el futuro tanto de la familia como de la comunidad.

Por esto mismo, el proyecto individual y colectivo que se desarrolla en la ciudad se ve interpelado cuando el fin del ciclo productivo del mineral se vuelve inminente, lo que se manifiesta en una serie de restricciones fundamentales. Por tanto, desde la lógica económica estas ciudades minero-industriales como Lota comprometen una contradicción básica y esencial respecto del habitar y de la comunidad: son finitas como proyecto. A pesar de esto, hay una desatención cotidiana porque las proyecciones de sus habitantes superan esta expectativa temporal que les caracteriza y en su imaginario no tienen fecha de caducidad, ya que se orientaron al futuro, al valorar y validar positivamente parte de lo que ahí se construía y ofrecía, especialmente en aquellas del modelo Company Town, como fue Lota.

Entonces, antropológica y sociológicamente el sufrimiento vivido corresponde al descentramiento ritual de la vida cotidiana, porque se pone fin a un pacto entre el hombre y su mundo, el hombre y la ciudad, el hombre y la naturaleza. El dolor se acentúa cuando las nuevas generaciones no pueden ser empáticas con las claves del pasado y la sociedad nacional las percibe y siente como culturas relictus y fuera de la historia. 
En las páginas siguientes se revisará en perspectiva histórica el proceso de declinación de la ciudad de Lota, monoproductora de carbón y atravesada por el sino del sufrimiento.

La formación de una ciudad industrial y de una cultura del trabajo

Ubicada en el centro sur de Chile, en antiguos territorios mapuche, al lado sur de lo que fue la frontera natural del río Biobío, se emplaza Lota, o Louta, un pequeño caserío fundado en 1852 y en el que se desarrolló la explotación minera subterránea energética más importante de Chile: la del carbón. El caserío se constituyó en la primera ciudad industrial del país y en ella, antes que en Santiago, se implementó, producto de la potencialidad del trabajo extractivo de carbón, la telefonía de superficie y subterránea en los túneles, el alumbrado con una planta hidroeléctrica, redes de gas, calefacción domiciliaría, ascensores para bajar y subir a los piques, un tren subterráneo para conducir a los trabajadores y extraer el mineral (Figura 1).

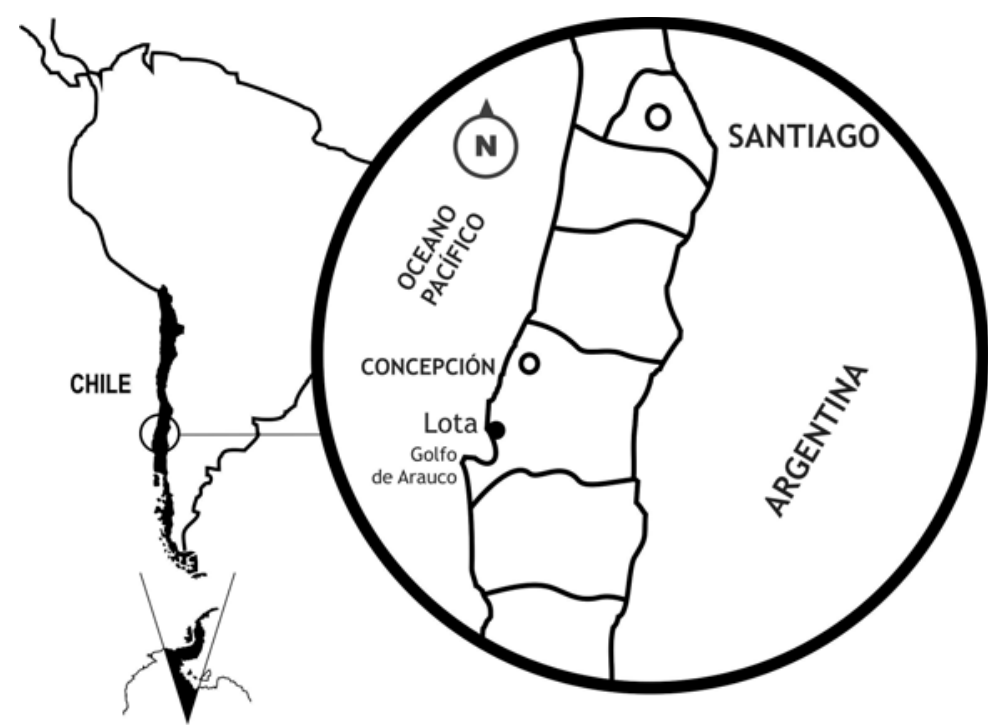

Figura 1. Mapa referencial de localización de la ciudad de Lota, en la Región del Biobío. 
A partir de la explotación del carbón, se produjo una integración productiva que hoy llamaríamos un holding, compuesto por la empresa minera, una flota de transporte naviero, ferrocarriles de superficie, muelles y emplazamientos portuarios, una fábrica productora de vidrio, de cañerías, de ladrillos refractarios para las fundiciones de cobre y de cerámica doméstica y ornamental. Además de una industria forestal para contar con madera en el trabajo de la mina.

Por la complejidad y vanguardia de su desarrollo, Lota se configura capitalista y con ella se inaugura la producción nacional en cadena. Es gracias a esta diversificación que, a finales del siglo XIX e inicios del XX, se constituye como una ciudad emergente con importantes servicios relativos tanto a las demandas industriales como a las domésticas de sus habitantes. Su desarrollo y actividad extractiva trascienden su territorio y se irradia paradigmáticamente conectándose con el norte, centro y sur del país, ya que Lota fue, por antonomasia, la ciudad monoproductora de riqueza energética que con su carbón alimentó fundiciones y calderas de ferrocarril y de los navíos.

La ciudad, desde su origen tuvo una lógica constitutiva. Ésta se expresa en términos de Di Méo y Buléon (2005), como una fuerza económica, ideológica y política, material y simbólica, que se encuentra espacialmente organizada en zonas industriales, habitacionales y comerciales, manifestando un dinamismo marcado por la institucionalización de las prácticas laborales y las actividades sociales y culturales "que mapean el imaginario simbólico de los ritmos vividos por sus habitantes en múltiples territorios" (Rocha; Eckert, 2011, p. 108, traducción nuestra). Construida e identificada tempranamente por las luchas sociales en consonancia con los procesos de diferenciación social, compromisos políticos y las acciones normadas, con población desafiante y abierta a la integración laboral. El producto de esta razón moderna permite la emergencia de una nueva clase social: el proletariado chileno. Por tanto, Lota se desarrolla en clave capitalista y se constituye como ícono de la revolución industrial local. ${ }^{1}$

\footnotetext{
La intensidad de la actividad contó, para la extracción de carbón, con unos 6.200 trabajadores en tiempos de la administración de la familia Cousiño -en un universo de 10.000 dedicados al rubro en el siglo XIX-, unos 18.000 trabajadores en la década de $1950 ; 16.000$ en 1973; 5.971 en 1982; y en 1990 menos de 5.000. Los cambios en la plantilla de trabajadores están asociados a las vicisitudes sufridas por la industria carbonífera, a los ritmos de producción y fases de declinación de acuerdo a tres elementos estructurantes: la matriz energética del país, que da cuenta de los cambios en la demanda ligados
}

Horizontes Antropológicos, Porto Alegre, ano 20, n. 42, p. 237-264, jul./dez. 2014 
Lota se desarrolló en torno al trabajo y correspondió, durante mucho tiempo, a la organización más fuerte que haya podido impulsar el capital chileno (Astorquiza, 1952, p. 15). Es en este enclave productivo donde se generó la salarización, la temprana inserción de los jóvenes al mundo laboral y el trabajo infantil, integrados a verdaderas cadenas humanas, ${ }^{2}$ lo que termina imponiéndose como pauta de socialización intergeneracional y tradición familiar. Los indígenas y campesinos reclutados como trabajadores fueron sometidos a una maquinización y adiestramiento corporal y a una cultura horaria cronológica, propia del rigor de la industrialización como precondición para la integración social.

En lo fundamental, a través de la actividad minera, en Lota se desarrolla una cultura del trabajo que penetró todos los intersticios de la ciudad. Se constituyó una clase social proletaria, con identidad laboral y con componentes ideológicos socialistas y sindicalistas, apoyada siempre por periódicos y folletos doctrinarios que divulgaron el ideario socialista. El trabajo se realizó en la profundidad de la tierra, de manera submarina y con una extensión que puede medirse en kilómetros; es riesgoso y distinto, y la actividad es considerada "titánica, heroica y fabulosa" (Corvalán, 1992, p. 129). Los hombres, entregados con incertidumbre a las honduras de la tierra y la obscuridad, encomendados a sus convicciones religiosas, bajaban casi 500 metros en forma vertical en "jaulas" (ascensores) para ingresar al túnel, llegando a internarse más de 15 kilómetros en forma horizontal bajo el océano; de ahí que el trabajo diario -mezcla de fuerza física y habilidadpareciese una eternidad y que los ojos se encontraran siempre bien abiertos, los oídos alertas ante cualquier derrumbe en las galerías y el olfato aguzado para reconocer la presencia del gas grisú o viento negro, causante de grandes tragedias (Figura 2).

al desarrollo de la industria; la incorporación de tecnología más eficiente; y los costes de producción, lo que tiene incidencia en la demanda de fuerza de trabajo y en la generación de la riqueza en la ciudad.

2 Entre las personas de más edad, es fácil encontrar referencias a los años 30 en los que el ingreso al mundo del trabajo se producía a los 12 años. Esto significaba un aprendizaje en torno al trabajo minero desde tareas menores como los mandados o labores de apir (sin especialización) a aquellas más complejas como disparador o mayordomo. 


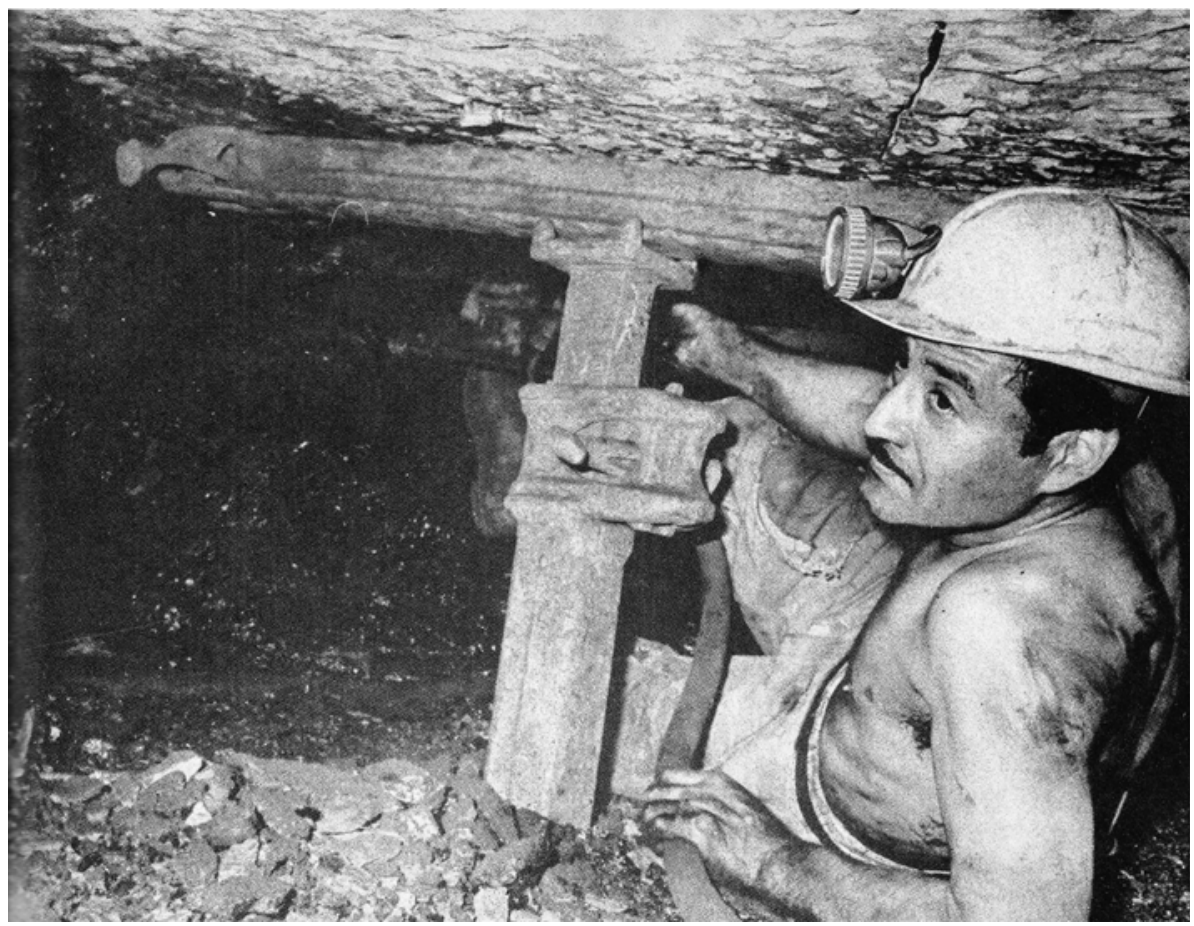

Figura 2. Irabajador al interior de la mina.

Desde una perspectiva etnográfica y etnológica, este modo de trabajar se constituye en una actividad tradicional, repetitiva, reconocida y sedimentada en el tiempo; la forma de trabajo con sus eternas rutinas y rituales, el riesgo al interior de la mina y el que no haya "en el mundo mayor silencio, a menos que lo interrumpa una gotera persistente, vil recordatorio de que el océano está encima" (Rivas, 2000, p. 6) es lo que hace que cada día se envejezca de manera acelerada y se muera un poco más en un trabajo que presenta históricamente pocas variaciones por los esfuerzos físicos comprometidos.

El proceso de trabajo define y estructura a través de generaciones la identidad de sus gentes y la de la ciudad con el carbón, al transformarse en potentes elementos de distinción frente a cualquier otra tradición minera. Con el trabajo en común y en estas condiciones de arrojo, donde -señala Pedro- "siempre se siente miedo y donde no todo está bajo control”, se generan compromisos de 
lealtad que llegan a ser evidentes a través del tiempo. Así, lo que aflora a la superficie es una memoria de lo que la mina esconde, de turnos sincronizados, de cuadrillas de trabajadores convertidas en confianza y amistad, de acercamientos religiosos y políticos, de millones de horas hombre extrayendo carbón; de dedos que arañaron la riqueza, de infinitas cavilaciones que nadie podrá registrar, de las marcas en el cuerpo propio y en los ajenos, de los huesos resentidos.

La mina, desde la riqueza material y simbólica, estructuró la ciudad de Lota y el repertorio de posibilidades sociales, culturales, económicas, sanitarias, educacionales y habitacionales durante generaciones. La deja a merced de ella y le permite desplegarse como Company Town en toda su configuración socio-espacial así como en su diferenciación ocupacional por actividades y entre trabajadores de la empresa y los subcontratados. Los primeros vivieron en Lota Alto, en la ciudad planificada, y los otros en Lota Bajo que fue su periferia. ${ }^{3}$

En estos espacios urbanos, la vida cotidiana revela extensivamente todo su sentido y simbolismo. La existencia colectiva se constituyó a través de prácticas, acciones, rutinas, modos y comportamientos habituales y regulados que en su conjunto fueron estructurando esquemas reflexivos, aprendidos y repetitivos que estabilizan el espacio social y otorgan identidad a los lugares. En su fluir, la experiencia, institucionalización y posicionamiento del rol minero va decantando en el control del espacio en términos físicos y psicológicos. $\mathrm{Y}$ es esta habitualidad, desplazamiento y apropiación de los trabajadores y habitantes lo que establece el vínculo con territorios específicos, delimitando, marcando y circunscribiendo las posibilidades de ser de cada persona en relación a la familia, al trabajo, a la clase, al sindicato, al partido, al género, al culto religioso y a las relaciones sociales.

Este día a día estructura la vida y la organiza en función de la actividad productiva, lo que imprime una orientación y sentido a las acciones y decisiones de los actores, que permite apreciarlas en lo ideológico, lo organizativo y su articulación social. Lota, como todas las ciudades mineras (Eckert, 2012; Garcés, 1999, 2007, Rodríguez; Miranda, 2008, 2009), se destacó por sus rasgos únicos que decantan en una especificidad cultural y en esquemas

\footnotetext{
3 Lota Alto corresponde a la Company Town, donde se concentraron los servicios industriales y comunitarios como el hospital, la iglesia católica y las construcciones habitacionales con arquitectura inglesa y segregada según roles y jerarquías ocupacionales. Lota Bajo corresponde a la parte de la ciudad informal y de autoconstrucción. Además, aquí se localizaron los servicios públicos.
}

Horizontes Antropológicos, Porto Alegre, ano 20, n. 42, p. 237-264, jul./dez. 2014 
de sociabilidad muy estables, donde se constituyen proyectos vitales con clara orientación de futuro.

Es así como el aprendizaje y la experiencia del trabajo minero se transforman en un modo de vida, en rituales, en formas de nombrar y registrar la experiencia dentro y fuera de la mina, en relaciones estables y permanentes tanto en los sindicatos como en la vecindad y en el intercambio diario en la ciudad, en la ocupación del espacio urbano, en el uso de los servicios, en los lugares de sociabilidad masculina como las cantinas, los prostíbulos y los de las prácticas deportivas, en la especificación de los roles de género, las expectativas sobre la vida como proyecto vital, un cierto deber ser, ya que todo hijo de minero también debía serlo y sus hijas debían casarse con uno de éstos. Cada día, tres turnos ininterrumpidos de obreros caminaron por las galerías de los pabellones con el hollín impregnado en las fachadas de cada vivienda, la ropa que flamea colgando de los tendederos, las chimeneas humeantes y el pan diario salido de los hornos que corresponde a un espacio de sociabilidad femenina.

\section{Utopía y eutopo: la derrota de una clase}

Se desgarran las campanas

$Y$ arde un fuego funeral

Mujer saca tu pañuelo

Y echa el llanto a la mañana

Que la mina está de duelo

$Y$ algo tuyo ha de enterrar:

Lo atrapó el carbón maldito

Que así nos da fuego y pan

(Patricio Manns, 2005, p. 111)

En Lota siempre se vivió con fuerza la tragedia y el luto asociado al trabajo, el dolor de la pauperización, el conflicto, la esperanza por un mundo más justo y con más reconocimiento, reivindicaciones representadas por las organizaciones sindicales y políticas. El cuerpo exhausto buscó por décadas dejar atrás las lámparas de aceite, la ropa confeccionada con sacos de harina, los cascos de cuero y ojotas usadas en vez de zapatos de seguridad, jornadas de ocho horas diarias, alcanzar una jubilación a los 25 años de trabajo.

Sin embargo, la fatalidad de la amputación de una extremidad por un derrumbe, un tiro mal ejecutado o la fractura de columna e invalidez total, 
también formaron parte de su sino trágico. La muerte, como elemento propio del riesgo del trabajo subterráneo, es un rasgo omnipresente en esta sociedad, tal como se expresa en su cementerio y en los recuerdos colectivos sobre accidentes al interior de la mina o hechos luctuosos.

La lucha y movilización sistemática por mejorar las condiciones de trabajo y de vida son los elementos clave que forjan el heroísmo y la épica que sostiene la imagen más permanente de la ciudad de Lota y la identidad de sus habitantes a nivel nacional. Esta impronta le permite al movimiento social situarse en el tiempo con relación al pasado y al futuro, proclamando una pertenencia y un lugar en la historia de los movimientos sociales de Chile. Así, siempre destacan los mismos términos para configurar la identidad filial de Lota: un contrapunto entre un presente alineado con la pobreza y la injusticia social y la esperanza de un mundo mejor, canalizada a través del sindicato y el Partido Comunista. Es por esto que cuando se explora la memoria colectiva en la actualidad, ésta mantiene vigente la idea de la huelga, la asamblea, la organización, el sindicato, el partido, el orden, la alianza, el bien común, la solidaridad y la lucha, como fortalecimiento de la autoestima y visión anticipadora de un futuro superior. Así, se desarrolló una cultura laboral que vivió el conflicto entre capital y trabajo y buscó formas de resolución total o parcial del mismo y, en esa medida esclareció y auguró un cierto porvenir para hacer y vivir la ciudad y en la ciudad utópica.

En estos términos, Lota se constituyó como una "ciudad roja", con una clara orientación comunista pro-soviética en su utopía, por lo que en su proyecto se necesitaba alcanzar el poder (Alcalde, 1973). Asimismo, su eutopo fue la Unión de Repúblicas Socialistas Soviéticas. Coherente con aquello, la movilización y las grandes huelgas impulsadas por el Partido Comunista se transformaron en la estrategia, y la URSS en la tierra prometida. Su lucha sindical y partidaria es local, nacional y con vocación internacionalista; se ofrenda a los trabajadores de Chile y el mundo.

La actividad sindical y política tuvo entre sus momentos emblemáticos la promulgación de la llamada "ley maldita" o "ley de defensa de la democracia", la que aplicada en el gobierno de Gabriel González Videla significó el destierro de dirigentes sindicales, la cesación de cargos públicos de todo militante comunista y la proscripción de su Partido (Ley n ${ }^{\circ}$ 8.987, de Defensa Permanente de la Democracia, publicada en el Diario Oficial de 3 de septiembre de 1948). 
En 1960, entre muchos otros conflictos a lo largo del siglo, se desarrolló un movimiento huelguístico que es conocido dentro de la historiografía como la "huelga larga". Esta, se extendió por 97 días, los trabajadores demandaban, ya como una cuestión recurrente, mejores condiciones de trabajo y de vida, anticipando con ello un escaso porvenir laboral y para la ciudad de Lota. Miles resistieron junto a las familias con ollas comunes y enviaron a sus hijos a padres sustitutos, en otras localidades, mientras luchaban. Marcharon 35 mil personas $40 \mathrm{~km}$ hacia Concepción, desafiando el bloqueo alimentario del gobierno de Jorge Alessandri Rodríguez. Sin embargo, la tierra interrumpió la aspiración: un terremoto ocurrido el 21 de mayo llevó a los trabajadores a concluir su huelga, la que fue el último movimiento de importancia, hasta lo que sería el anuncio del cierre de la mina.

Una década más tarde, bajo la presidencia de Salvador Allende, se promulgó la Ley No 17.450 del 16 de julio de 1971, que ordenaba la concentración y estatización de todas las explotaciones carboníferas, definiéndola como "dominio absoluto, exclusivo, inalienable e imprescriptible del Estado sobre todas las minas". Para los trabajadores del carbón y la ciudad de Lota, ésta Ley se consideró el último gran gesto del Estado chileno con sus reivindicaciones (Figura 3).

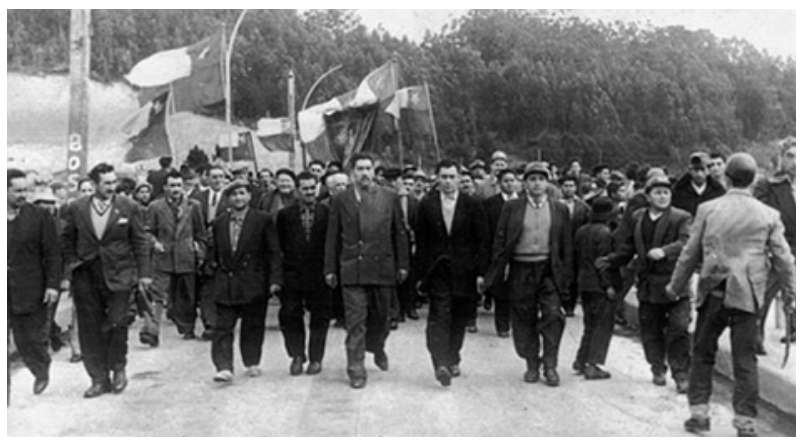

Figura 3. Mineros huelga larga, 1960. Memoria chilena, BNCH.

Sin embargo, el movimiento social debió enfrentar tres hechos que aniquilan violentamente los proyectos existenciales, sindicales y políticos, porque desaparecen las instituciones que canalizaban las expectativas, los referentes 
utópicos y los eutopos: el Golpe y dictadura militar; la caída de los socialismos reales; y, el cierre de la mina (Medina, 2010). La dictadura militar en 1973, terminó con los esfuerzos y lucha de todo el siglo XX por alcanzar el poder y construir el proyecto socialista en el país, controlar la riqueza nacional y mejorar las condiciones de vida por las que se habían comprometido políticamente los sindicatos y partidarios populares. Proscritos los partidos, prohibida la actividad sindical, y cerrados sus medios de comunicación, se desarticula la base social y política del movimiento que sustentaba el dinamismo de la ciudad. Algunos de sus dirigentes y militantes sufrieron la muerte, la persecución y el exilio, otros fueron detenidos y despedidos de su fuente laboral, quedando Lota indefensa frente a la arbitrariedad y violencia, y sin la masa crítica que ayudaba a pensar y construir la ciudad.

La caída del muro de Berlín y el fin de los socialismos reales en 1989, junto con el desmembramiento de la URSS, es la salida de escena de un paraíso posible, de una imagen arquetípica y de una convicción que orientó la vida de generaciones. Ya no hay donde mirar, no hay proyecto que inspire ideológicamente la acción política de los militantes del Partido Comunista de Lota.

Transcurridos siete años del fin de la dictadura, el 17 de abril de 1997, bajo el gobierno de Eduardo Frei Ruiz-Tagle, el Presidente de Empresa Nacional del Carbón (ENACAR) Jaime Tohá González formuló un lacerante anuncio: el cierre constituye la "única opción responsable" para una empresa del Estado, dada la escasa rentabilidad que la extracción de este mineral le reportaba. ${ }^{4}$ Con ello se consuma el cierre irreversible de la mina, esta fue inundada y toda la maquinaria puesta en venta. ${ }^{5}$ Más allá de la tragedia del desmantelamiento de las instalaciones, es la vida la que se arruina y desmorona

\footnotetext{
4 Al menos desde la segunda década del siglo pasado, se anunciaba la vulnerable condición monoproductora de Lota. Ya no era posible reconfigurar la estructura interna del proceso productivo, dado el aumento de los costes de extracción (internación más extensa bajo el mar, el refuerzo de galerías, valores de la madera para el envigado) que hacían poco competitiva la extracción del carbón frente a otras fuentes energéticas y a la importación de carbón colombiano. Es la obsolescencia general de las condiciones bajo las que opera la industria la que entra en crisis y que le condena a desaparecer. Las navieras, el ferrocarril y las fundiciones, que eran las grandes consumidoras del mineral, ya no requerían de esta fuente energética.

5 Los trabajadores y la ciudad completa se movilizaron contra la medida, a pesar que ya quedaban pocos obreros y técnicos en las últimas faenas. Después de importantes negociaciones entre los sindicatos y el Estado, éstos no lograron revertir la medida y solo consiguieron "jubilarse con la doble". Esta expresión significa que, además de una pequeña compensación económica, lograron duplicar su jubilación, la que en la actualidad alanza a una cifra cercana a los USS 300 .
}

Horizontes Antropológicos, Porto Alegre, ano 20, n. 42, p. 237-264, jul./dez. 2014 
en su ligazón con la historia y la memoria colectiva. Toda la existencia se contrae en sus articulaciones cotidianas, y es puesta en entredicho como proyecto y como esfuerzo histórico al desplazar a generaciones de lotinos a una condición de actores secundarios.

Estos tres eventos, instalados en la memoria colectiva como actos existencialmente dramáticos, constituyen los signos de la derrota de una clase asociada a un proyecto político, de una cultura del trabajo y de una ciudad que debe su existencia a la mina.

Con un presente sin trabajo minero se rompe el vínculo indisoluble con la actividad que prefiguró la identidad social y urbana, especialmente en lo que corresponde a la situación contractual (existencial) con la naturaleza, que habla de un pacto productivo y laboral, que es el de la imagen de la mina como vientre para sustentar la vida en común. Esta disolución se representa también en los volúmenes deteriorados de la arquitectura de la ciudad, que grafican la detención de la actividad industrial y de los servicios asociados y complementarios que perdieron su función, quizá como metáfora de lo que acontece en la vida de cada extrabajador que no puede canalizar su saber. Enfrentados los sujetos a un mundo postcarbón, a una mayor precarización y a proyectos estatales de reconversión laboral se produce una relocalización temporal en el imaginario tanto de las cuestiones materiales como simbólicas, ya que no hay construcción de la esperanza con los recursos y capacidades locales debilitados por los eventos señalados, pues Lota sólo fue minera y no depende de sí misma. El fin del ciclo minero la transforma en una ciudad dañada, expulsora y residual.

\section{Las marcas de la ciudad postcarbón: ruinas y espera}

Como ocurre con toda tradición que declina, la experiencia intergeneracional de ser minero se confronta hoy con la peor de las situaciones: "la de mirarse las manos y saber que ya no sirven para nada, la de mirar el reloj y saber que la hora que viene será igual a esta que está, la de pensar en el día de mañana, y saber que será tan vacío como el de hoy" (Saramago, 2008, p. 348349). ¿Qué hacer con la propia vida? ¿Qué hacer con la ciudad? ¿Hacia dónde mirar? El cierre de la minas ubica a la población de cara a la incertidumbre y a nuevas angustias, esta vez definitivamente a todos en la superficie, obligándolos a revisar el contenido de la propia vida como el de los espacios que 
contenían la memoria del trabajo y la recreación y de los particularismos de la ciudad y sus gentes.

Llegado el momento que comienza la declinación de la ciudad de la mano de los cambios en la estructura productiva, se ve afectada la población y la infraestructura, lo cual se expresa en: 1) caída demográfica,${ }^{6}$ 2) baja inversión pública y privada, 3) importante diferenciación entre generaciones, 4) obsolescencia de identidades laborales, 5) fractura en las orientaciones de la socialización, 6) pérdida de prestigio y desaparición de sus actores históricos, 7) cambio de los interlocutores, ya que se quedan sin empleador, 8) desaparición de los espacios de interacción extralaborales. A lo anterior, se suma la decadencia de un proyecto de vida en torno a la ciudad, que en sentido estricto corresponde a cómo ésta se arruina en paralelo a una vida que se minimiza en sus opciones y sentido de arraigo, en la medida que su imaginario moderno se vuelve insustentable.

Entonces, el sufrimiento aparece en Lota como la gran emoción de la ciudad y sus gentes, en contradicción con aquello que fue pensado por los hombres y las mujeres como infinito, permanente y próspero, donde este espacio era visto como refugio para concretar el proyecto vital. Mientras que la ciudad minera de la máquina y el engranaje, no es más que una experiencia temporal finita, efímera e incontrolable por los trabajadores, la ciudad-vientre es una forma de sentimiento y de situarse en y frente a ella, aprehenderla, vivirla, recorrerla, agradecerla y padecerla en sus restricciones y bonanzas; y, la ciudad-industrial, representa aquellas fuerzas que están más allá del control que pueda ejercer una o más generaciones sobre las condiciones de necesidad que dieron origen al emplazamiento urbano industrial.

De tal forma, la declinación de la ciudad minera de Lota se manifiesta como una violencia a la biografía. Esta es historia, pasado, experiencia, es un ejercicio rememorativo de contar una forma de vida ligada a una expectativa de futuro; es ejercitación mimética, secuencia temporal y orden, estructuración de la vida, identidad; es afirmación de interioridad y de sí mismo. La biografía es el nexo entre el interior y el exterior, entre lo público y lo privado. En este sentido, lo público es lo social y lo político, y esto es lo que se desmorona

${ }^{6}$ La ciudad ha pasado de 80.000 habitantes a comienzos de los años 80 a una cifra inferior a 40.000 antes que finalizara la primera década del presente siglo.

Horizontes Antropológicos, Porto Alegre, ano 20, n. 42, p. 237-264, jul./dez. 2014 
y sucumbe desde la perspectiva del cambio con el cierre de la mina como eje estructurante de la vida en común. Si existe dolor, es porque las trasformaciones hacen desaparecer de la presencia del mundo todo cuanto no es actual, es decir, la obsolescencia de la experiencia y de las infraestructuras urbano industriales les arrebatan la historia, porque les impide recuperar el lugar en el mundo, ya que, por ejemplo desapareció el sindicato, aunque permanezcan muchas de sus sedes, y los partidos tienden a ser superados en su convocatoria por las iglesias evangélicas (Figura 4).

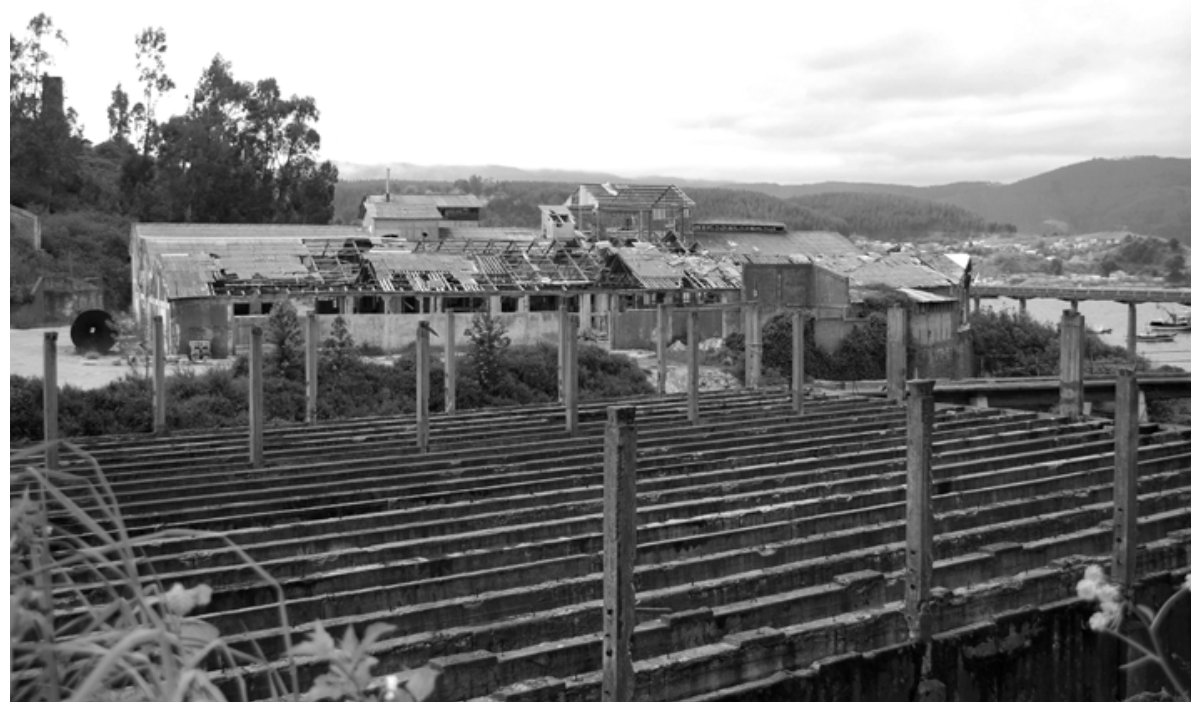

Figura 4. Ruinas del complejo industrial de Lota. Fotografía de los autores.

El trabajo en la mina ofreció el encuadre de los objetos de referencia desde la cual se constituye la experiencia y la identidad. Sin éstos, encontramos unas figuras extraviadas que retornan una y otra vez sobre lo que se erigió la vida y que ya no es encontrable en la cotidianeidad desritualizada. "Se trata de ciudadanos extirpados de sus antiguas pertenencias" como sostiene Déotte (1998), porque lo que se juega en la proximidad de las relaciones 
con los objetos, la arquitectura, el trabajo, las rutinas, las prácticas, es el aprendizaje o el "saber usar" las cosas e instituciones del mundo en el que se ha configurado la biografía en términos de Heller (2002).

De este modo, el dolor y el sufrimiento aparecen como impronta emotiva de la ciudad, porque han desaparecido la estabilidad laboral -que otorgaba el Estado como dueño de la mina- y los recursos necesarios para la sobrevivencia, procurados por el trabajo. Entonces, gran parte del sufrimiento se sitúa en el quiebre de las estructuras que afianzaban y contenían las existencias, y en el conjunto de actividades ritualizadas que crearon las condiciones para la reproducción de lo cotidiano. La continuidad de sus formas y prácticas, cuando son absolutas crean exigencias para que la formula sea de "día en día" o "cada día" hasta establecerse como el modo de vida de la comunidad. En estos términos, el modo de vida simbiótico establecido entre ciudad-mina y mina-ciudad, corresponde al ámbito de lo inmediato y no de aquello que lo excede; los mineros de Lota siempre enfilaron en silencio y conspirativamente contra la injusticia social por kilómetros bajo el océano, conscientes de que su cuerpo se resentía, para configurar tanto el mundo de la subterra y después narrarlo en el subsole.

Hay un saber cotidiano que se constituyó como acumulación de conocimientos que se han interiorizado para moverse en el espacio como indica Heller (2002, p. 526). Por tanto, al modificarse las condiciones estructurales en el que ese saber tiene vigencia y sentido, se cuestiona y revelan las dificultades para prospectar, percibir y flexibilizar las miradas con las que se ha configurado la identidad, para penetrar otros mundos y experiencias, así como para sobreponerse e internarse en otros saberes cotidianos. Los quiebres son más agudos y dolorosos conforme se vuelve más notoria la división social del trabajo y el repertorio de roles dominados es más limitado, que en Lota aconteció por lo que la vida es más difícil de readecuar o imposible de restablecer, especialmente cuando no hay posibilidad de retorno a las condiciones preexistentes propias de la cultura y la conciencia obrera.

Por lo anterior, cuando los habitantes viven como una pérdida de sentido la transformación, hombres y mujeres comienzan a hablar desde el yo joven. La nostalgia de esa trayectoria corresponde al reconocimiento de que algo está ausente, y eso no es más que el espacio vacío que dejó el referente social. El universo léxico de la cultura del trabajo del carbón se convierte en residual, ya que nombra objetos, procesos y prácticas que sólo están en un mundo que ya no tiene correlatos empíricos. 
El que la ciudad ya no produzca y no genere riqueza es lo que provoca su ingreso a un proceso de declinación material. La ruina es un espejo de 1s gente empobrecida. Por ello, cabe preguntarse: ¿Qué se puede controlar de la propia vida dentro de una ciudad que hasta ahora se presenta sin alternativas y no sustentable?

La desaparición del territorio subterráneo como espacio laboral y cultural en Lota, exige reemprender la vida en superficie. Así, para los hombres del carbón no es fácil reorganizarla ni esclarecer desde dónde y con qué argumentos se puede reiniciar un camino para dar un nuevo sentido a la existencia cuando su territorio del hacer y el saber ligado al subterra desaparece, o señalar con claridad cuánto y qué se puede sacar de la mente para que las incomodidades provocadas por la alteración de su singularidad se mitiguen y lo no resuelto encuentre otras opciones. Estos viejos y especializados trabajadores no saben por dónde empezar: simplemente por edad, por enfermedades profesionales, por ganas, por experticias que entran en desuso, van transformándose en residuos.

La escena de lo nuevo conduce necesariamente a la reescritura de la biografía, porque así como el tiempo les ha llevado la mitad de la vida en el trabajo y en la profesionalización del rol junto con los compañeros de sección y turno, también viene por lo que les resta por vivir. Entonces, inicialmente la pregunta es: ¿Hay posibilidades para la normalización cuando se rompe el vínculo mina y ciudad y se pasa de trabajador asalariado a trabajador libre? ¿Cómo se repara la existencia frente a la desaparición del proyecto histórico del movimiento social al cual ofrendaron sus vidas?

La reconversión laboral fue un procedimiento ofrecido por el Estado a través del cual se pretende reincorporar a los trabajadores, los que teniendo habilidades específicas y validadas como mineros, no tienen posibilidades de ejercerlas por razones externas a ellos y porque carecen de un repertorio de alternativas ocupacionales para insertarse en el mercado de trabajo. Por ello, puede entenderse que el proceso de reinserción laboral haya sido en extremo difícil, ya que no hay muchos márgenes para la reinvención cuando lo físico primó por sobre otras habilidades; siendo escasos los éxitos de exmineros que lograron un proceso de incorporación a otras actividades productivas como la pesca y el trabajo forestal presentes en la región. De Dinechin (2001, p. 79) agrega una observación importante para este tipo de procesos: "la industria chilena es cada vez menos consumidora de empleos poco calificados y cuando lo es, ella los reserva a los jóvenes con vistas a capacitarlos". 
Con el fin de la actividad carbonífera local, los procesos de jubilación se hicieron recurrentes, y las actividades laborales esporádicas y sin contrato constituyeron algunas fuentes de ingresos, aunque la gran mayoría ha vivido de las pensiones. Mirado el proceso con 15 años de distancia, extrabajadores narran su reinserción con escaso o nulo éxito, de fracaso en sus emprendimientos como taxistas, microempresarios de la locomoción colectiva, peluqueros, contratistas para empresas forestales o de desarrollos como mueblistas y comerciantes minoristas. Otra dificultad, escasamente considerada para un nuevo trabajo y reemprendimiento en superficie, estuvo asociada a sus problemas de salud, ya que de manera coincidente destacan enfermedades profesionales que hacen imposible la reinserción: várices, problemas a la columna, silicosis y artrosis en las rodillas.

Además, en la reconversión subjetiva aparece la leyenda como elemento conspirador y de identificación histórica, señala un exdirigente sindical: "cuando uno va a buscar trabajo afuera, Lota nos juega en contra. Lota o lotino es sinónimo de ser comunista, conflictivo; entonces, hay que cambiar la dirección de residencia [...] nos dicen que son buenos los antecedentes, pero que podemos ser conflictivos". Ahí aflora nostálgica y dolorosamente el recuerdo de la organización y movilización social y política con toda nitidez en su dimensión teleológica.

Lo anterior muestra que deviene una complejidad distinta plantearse el proceso de reconversión laboral del minero como una cuestión formal y técnica, a plantearlo como una reconversión cultural, una reescritura biográfica y de modos de vida, incluso lingüísticos, de estos actores sociales. Antropológicamente hablando, esto implica mirar y considerar la ciudad y sus habitantes desde aspectos existenciales, anímicos y temporales, ya descritos en las páginas precedentes, los que atañen a la construcción de la subjetividad y a un repertorio de referencias históricas ligadas a sus propias leyendas, mitos y éticas, a la construcción de su imagen y autoestima.

El no encuentro o la no generación de una alternativa efectiva y eficiente de reemplazo al lugar ocupado por el mundo del carbón, es decir, de lo que fue una cultura del carbón, convierte a la ciudad en un lugar de reproducción de los cuerpos y existencias dependientes del Estado. Gran parte de la población, ligada directa e indirectamente con la minería, son personas que reciben subvenciones, lo que instala una forma particular de envejecer sin lugar dentro de la comunidad, generando además un delta generacional imposible 
de compatibilizar con las expectativas y el vértigo juvenil. Esta subvención obligada, gestada desde distintos planes y programas del Estado, es la que hace posible que aún subsista también la parte no minera de Lota: las actividades de servicios, el pequeño comercio detallista, la pesca artesanal y la feria. El salario indirecto se constituye en factor central a la hora de pensar Lota después del fin de la actividad carbonífera, ya que hay ausencia de trabajo productivo local, producto del fracaso absoluto del proceso de reconversión de la actividad minera. Esto último, tal como lo sostiene De Dinechin (2001), ocurre porque primero se cerró la mina y luego se pensó en qué hacer con su gente y la ciudad. ${ }^{7}$

\section{Las ruinas de la industria minera}

La arquitectura sigue a la historia como su sombra.

(Augé, 2003, p. 122)

Las marcas inscritas en los volúmenes de la arquitectura y la pérdida de función de los mismos como espacio semántico de la materialidad, son la revelación de las heridas, de cambios en la estructura ocupacional, de fluctuaciones en el trabajo, de pérdida de una cierta identidad y de una asociación con rutinas y lealtades que se configuran en el tiempo. Por tanto, si las "ciudades mineras se extinguieron en su sitio, después de haber agotado su sustancia, como el fuego" (Lévi-Strauss, 2006, p. 135), en perspectiva se trata de una materialidad llena de sentidos políticos, laborales, sociales, públicos y de acción colectiva en las que hay que hurgar. Las ruinas del carbón lotino nos sumergen en la fórmula de aquellas ciudades que esconden otras ciudades (Calvino, 1999), en un mundo de pertenencias y de identidad, de esperanzas, utopías e imaginarios que están en sus recuerdos.

\footnotetext{
Las opciones de Lota definidas como áreas de prioridad para su sustentabilidad como ciudad y como reconversión laboral para los cesados de la minería, fueron: madera, microempresa, pesca y turismo. Se pensó en una planta procesadora de algas, en un plan de obras públicas, en parque y condominio industrial con unas 15 industrias medianas para dar trabajo a 300 personas. Sin embargo, no resultó el proceso de recalificación y readecuación de las personas. No hubo interés en ser peluqueros, electricistas, soldadores y manipuladores de alimentos; no se desarrollaron otras experticias a través de nuevos conocimientos y habilidades tanto en la recapacitación como en la adaptación personal, mostrando, además, que a mayor edad de los extrabajadores, las opciones fueron más restrictivas y con menor recepción, lo que hace que para los desafiliados, la vejez se viva también con mayor dramatismo.
}

Horizontes Antropológicos, Porto Alegre, ano 20, n. 42, p. 237-264, jul./dez. 2014 
La ciudad postcarbón es simultáneamente un laboratorio y un museo. Atestigua el fin de una historia, de una clase, de una identidad laboral, una pertenencia, una forma de hacer amistad, de hacer familia y de recreación, anunciando una nueva ciudad. Pero, su ruina revela siempre la actividad fundacional. Por eso en Lota hay ruinas y gente arruinada: la estructura de oportunidades -en lo personal y familiar- sufrió un cambio fundamental, que su herida está abierta, lo que se traduce en una importante e irónica presencia de "instituciones imaginarias", como sedes de sindicatos y sindicalistas propios de un mundo anterior al cierre definitivo de las minas en el año 1997. Al romper el hombre de manera unilateral el pacto con la naturaleza (porque el carbón sigue existiendo), la ciudad habilitada con sus instalaciones para el trabajo productivo comienza a verse fantasmagórica, debilitada, vacía, deteriorada; se torna en un lugar de ausencias, en cuanto van transformándose en ruinas los vestigios de la arquitectura industrial: economato, teatro obrero, hospital, los pabellones de las viviendas, la cervecería, entre otros (Figura 5).

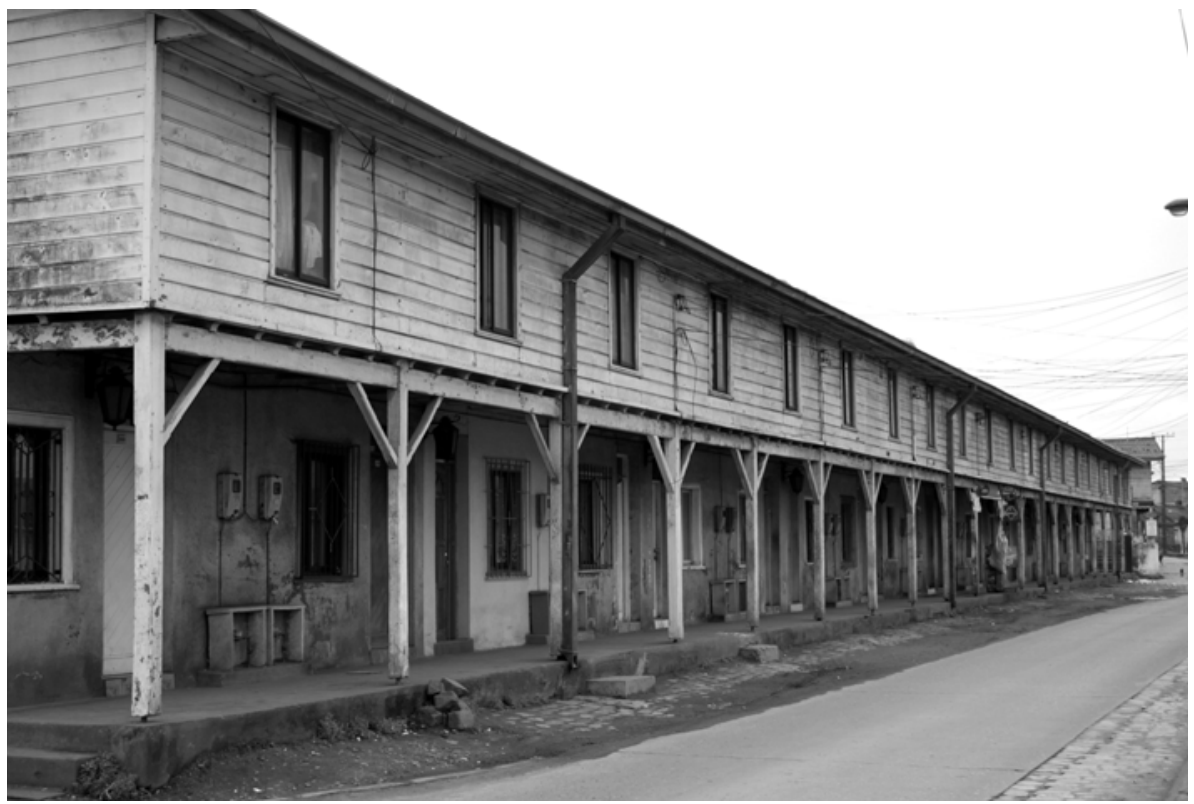

Figura 5. Pabellones habitacionales de los mineros. Fotografía de los autores. 
En Lota, la ruina como espacio de recuerdo es pasado, presente y futuro simultáneamente. Es pasado porque rinde tributo a hombres y mujeres cuyo mundo, o lo memorable de parte de éste, se encuentra en el vestigio de todas las infraestructuras fundadoras y principalmente de la mina. Es futuro, ya que contiene a través de rituales y encuentros en "sindicatos imaginarios" un interés comunicativo y una enseñanza para los más nuevos: esto fuimos, esto tratamos de construir, esto soñamos o en esto creíamos; esto podemos ser o esto queremos ser nuevamente. Todas estas fórmulas son efectivas, aunque limitadas en su impacto, porque el "nosotros" sindical y político utópico ya no puede influir decididamente, como lo fue en el pasado, en el curso de los acontecimientos, pues sólo queda lo pequeño y ordinario del cotidiano bajo el subsolé, es decir, el presente

Además, los vestigios de la industria minera dan cuenta que material y simbólicamente se ha perdido una función. Pero, como parte de la ciudad son un espejo; hablan tanto como callan. "La ruina es un ánfora. Es contenedor de una vida, de una biografía y una existencia que ya se fue, que ya no está, que no regresará. Es aquello que contiene recuerdos, que perturba y moviliza instantes, fugas, sombras y contraluces; se habla con ella, se siente su presencia, se duerme con ella y está viva y muerta a la vez. Es también un marcador temporal, se trata de un cierto retrato de los vencidos de la historia; de aquellos cuya vida fue arrasada por los cambios productivos, tecnológicos y laborales" (Rodríguez, 2010, p. 104).

La ruina connota más allá de su denotación, pues detrás de ella hay una emoción, un sentido muy subjetivo que arrastran sus habitantes. Es simultáneamente sinónimo de empobrecimiento y sentido de abandono en términos arquitectónicos que es lo más evidente cuando se recorre la ciudad. Da cuenta de un quiebre, de un trauma, de una actividad que queda en el olvido, de reconocimientos que ya no están, de oficios que se pierden en el tiempo, de una necesidad que ya no tiene su lugar, del deterioro de la condición de vida, de pérdida de solidaridad colectiva y de una forma de sentir, de un habla que se convierte en anecdótica, de una desintegración de la comunidad. Indican un proyecto incompleto biográficamente, concluido en tiempo industrial, una trayectoria existencial trunca y una tradición laboral que se extingue entre los recuerdos.

Hombres y mujeres enfrentados al sino de la existencia problemática, cuestionadora, angustiante en términos sartreanos, en la introspección y soliloquios, evalúan que hay cosas que llegan tarde, cuestiones sin resolver, apuestas mal concebidas, responsabilidades no ponderadas, ilusiones desbordadas,

Horizontes Antropológicos, Porto Alegre, ano 20, n. 42, p. 237-264, jul./dez. 2014 
rigideces e intransigencias poco estratégicas; cosas que no se ven en su momento, decisiones inoportunas, porque nadie se prepara para la, a veces, desastrosa expresión que puede revelar el presente.

Lota se encuentra dañada y está a merced de la inmediatez, lo que no permite dar contenido y sentido local a la existencia en términos psíquicos y políticos. Todos los materiales urbanos e industriales del pasado se ubican como ruina y tiempo trunco en medio de la ciudad; a sus habitantes les cuesta componer una imagen armónica que pueda tener como sustrato una fuente como el trabajo y las ideologías; hay desestructuración económica, despoblamiento, alto desempleo, hombres de manos en los bolsillos a todas horas, sin disciplina laboral y en un paisaje urbano deteriorado. Todas expresiones contrarias a las antiguas formas de vida de la comunidad y de las identidades personales y colectivas.

Si las ciudades proyectan emociones, Lota representa al pasado y es el pasado, porque apela a la representación de un hacer que ya no existe, en la que ya están de manera fosilizada las presencias del carbón. Las relaciones pueden ser representadas en otros frentes, pero no en su pacto, esto queda indicado tanto en la ruina como en aquellas instituciones que hoy tienen la categoría de imaginarias. Aquí se encuentran muchas sedes sindicales, que corresponden a espacios importantes y residuales del mundo del carbón; son organizaciones que mantienen vínculos en torno a aquello desaparecido, que operan como tejido de amistad y refugio de recuerdos. Sin embargo, no puede haber sindicato cuando no se tiene empleador. Quizá, lo más extremo de esta situación, sea un sindicato de extrabajadores de la película Subterra -un film chileno basado en las narraciones de un empleado de un almacén de la compañía minera- quienes después de la filmación se organizaron para demandar derechos laborales, aunque éstos hayan trabajado por unos días como extras.

La desaparición de la Company Town arrojó a sus habitantes al vacío, los dejó desvalidos y desamparados, desprotegidos frente a las vicisitudes propias del devenir cotidiano, obligándolos, además, a enfrentarse solos al duelo que significa la pérdida material y simbólica del escenario-ciudad que los alojó y contuvo mientras el proyecto funcionaba. El cierre del yacimiento supone la pérdida irrefutable de un imaginario, la confrontación a una existencia de ruina y la incapacidad de construir un proyecto vital. Es así como la experiencia en Lota es profundamente dolorosa y fragmenta a sus habitantes entre un pasado que ya no existe, un presente de ruinas y un futuro de incertidumbre.

Horizontes Antropológicos, Porto Alegre, ano 20, n. 42, p. 237-264, jul./dez. 2014 


\section{De la ciudad industrial a la ciudad de dios}

La condición residual de la experiencia que inspira el dolor, tiene que ver con el lugar perdido del mundo patriarcal, con la consideración disminuida de la propia identidad, la autoestima y la fuerza movilizadora. Los distintos eventos estructurantes del presente, acumulativos, residuales y traumáticos en la vida de lotinos y lotinas, requieren de lugares de integración para biografías que necesitan reescribirse y encontrar nuevos sentidos para una vida y cultura del carbón devaluadas social, familiar y generacionalmente, caracterizadas por la nostalgia más que por un sentido de realidad. El sufrimiento impone una urgencia: los hombres despojados de su vida cotidiana deben mitigar el dolor a través de mecanismos de comprensión, de apoyo y de solidaridad; restituir el sentido de comunidad y de iguales desarrollado en el trabajo de mineros. Hoy, la pregunta es saber cómo es posible activar y restablecer el valor de la existencia.

En la particularidad del mundo postcarbón, para algunos extrabajadores, la filiación a los distintos lugares de culto se observa como un espacio de alta frecuencia integrativa, y constituyen por excelencia el espacio donde se mitiga real o simbólicamente toda o gran parte de la adversidad, el daño, los déficits, y el abandono público y privado hacia la ciudad. En palabras del Presidente del Consejo Evangélico de Lota "si no hubieran existido las Iglesias, la ciudad así como cuando el salitre se acabó en el norte, las ciudades quedaron abandonadas, así hubiera sido Lota, abandonada" (Entrevista, 09/09/2012).

En éstos se llevan a cabo acciones prácticas "para ser felices"; la ritualidad y formalidad de la interacción ordena y orienta la relación con la familia y el trabajo, le provee sentido a la vida; el compromiso colectivo, la responsabilidad con la comunidad de fieles, el sentirse apreciado, y la incondicionalidad ante todo, otorgan identidad, fortalecen la autoestima y propician condiciones de autonomía. Cada grupo etáreo tiene su lugar, porque también son un espacio lúdico en una ciudad que no los tiene. Permitirían además, la reescritura de una identidad biográfica diferente, donde la referencia a la identidad citadina y laboral minera tiende a diluirse, e inclusive a estigmatizarse. Para muchos, el cierre de la mina representa la ruptura con una maldición heredada por generaciones. "La maldición de la mina" como la define un pastor pentecostal (16/09/2012), significa un quiebre con el sufrimiento intergeneracional de los cuerpos (abuelos, padres e hijos), ya que quién entraba a las faenas metafóricamente moría muy joven, y con el fin del trabajo minero, considerado 
el causante de todos los males, vicios y problemas sociales que recorrieron las calles de Lota: alcoholismo, prostitución, violencia y pobreza.

Como se ha afirmado en páginas anteriores, la salida de la mina de los trabajadores los dejó sin representación política, derrotados, sin elementos identificatorios de agregación, porque su vida se desinstitucionalizó (Castel, 2004). Salir de la mina los obligó a entrar al mundo desde otro lado; tras el fin de la actividad extractiva en 1997 se quedaron sin sus espacios de sociabilidad y ritualidad (cantinas, sindicatos, asociaciones deportivas y partidos políticos); con ello, la cultura laboral desaparece como cuestión colectiva, y en paralelo (re)emerge lo religioso como un componente histórico cultural de la identidad lotina, siendo las iglesias lo único que queda más institucionalizado, constituyéndose en un espacio de organización social-local por excelencia, esta vez de carácter religioso y no político. De esta manera, Lota sigue estando dominada por el sino de la espera, reinventándose en nuevas utopías para enfrentar el sufrimiento.

\section{Conclusión}

En Lota, definitivamente el carbón abandonó a su gente, y su gente hoy comienza abandonarlo como muestra palpable del fin del ciclo de vida del recurso y de la ciudad para desarrollar un proyecto vital. Fue el lugar donde se quería vivir y se buscó a través de la lucha política y sindical todo lo que se requería para hacer la vida. El carbón fue un vínculo esencial, marcado en cada cuerpo que bajaba a las honduras de la tierra y en cada chimenea humeante tanto de las casas como de las usinas de Chile. Su contribución a la historia social, política y económica al país no está en discusión, pero la reparación de sus vidas es lo que el Estado no pudo resolver. Las decisiones económicas, técnicas y políticas que permitieron el cierre de la mina después de 150 años, son distintas a aquellas que tienen que ver con el saber, el hacer y la cultura del carbón. Por ello, la emoción que proyecta la ciudad es de dolor y sufrimiento, porque ya no hay utopía ni eutopo que movilice la energía. Lo que no es presente, es todo pasado sin función.

Con el cierre de las minas de carbón, no sólo se pierde el trabajo que se dominó y respecto del que se fue experto, sino también la relación con el grupo de pares y todos los espacios comunes compartidos; se perdió el protagonismo, la visibilidad, la autoridad el poder patriarcal y se debilitó la imagen colectiva a nivel local y nacional. 
En los proyectos individuales y colectivos se encontraba contenido lo mejor de la juventud; la fuerza, las ganas, el deseo, el emprendimiento, el sacrificio y las esperanzas. Lota, a través del protagonismo sindical y partidario quiso llegar a un lugar; fue una ciudad hija de un mundo polar, de sujetos modernos, permanentemente movilizada para encontrar su destino, porque se imaginó que existían buenos lugares como los que habían en la URSS.

Hoy, el camino de los que fueron sus trabajadores no es de la casa a la mina, a la cantina, al sindicato o al partido como parte de la vida ritualizada. Hoy, es de la casa a la plaza y a la feria a encontrar a los otros que se quedaron sin lugar; pero, sobre todo, a alguno de los más de 300 lugares de culto evangélico existentes en la ciudad donde encuentran amparo para su vida dislocada, único lugar que todavía reúne una comunidad de iguales.

El sufrimiento se desencadena por un mundo que ya no está, de lo que no tiene retorno: el fin del trabajo en las minas, aunque la mina les haya consumido la vida. Además, porque desapareció el protagonismo y todo un léxico que proporcionaba identidad, ya que perdió los objetos que nombraba. El dolor y el sufrimiento no son accesorios ni parte sólo de la retórica del análisis social, pues irrumpe en la vida cotidiana. En este caso etnográfico, se destrozan los proyectos políticos, caen los referentes y los eutopos.

De acuerdo a lo señalado en este artículo, las historias no acaban porque alguien escriba la palabra fin. Pero, debemos reconocer que el carbón fue el demiurgo de los sueños de un mundo que se extingue cada día un poco más. A la antropología y la sociología le es dado moverse en este espacio de lo vivo y lo muerto que constituye el sufrimiento. La sombra que arrastran estos hombres se les escapa, y a estas disciplinas más que preocuparse por la fijación de las identidades se le está permitido referirse a estos cambios e intermitencias que buscan después refugio en otros lares.

\section{Referencias}

ALCALDE, A. Reportaje al carbón. Santiago: Quimantú, 1973.

ASTORQUIZA, O. El centenario de Lota. In: ASTORQUIZA, O; GALLEGUILLOS, O. Cien años del carbón de Lota: 1852-septiembre-1952. Santiago: Compañía Carbonífera Industrial de Lota, 1952. p. 15-16. 
AUGÉ, M. El tiempo en ruinas. Barcelona: Gedisa, 2003.

BAUMAN, Z. Vidas desperdiciadas: la modernidad y sus parias. Buenos Aires: Paidós, 2008.

CALVINO, I. Las ciudades invisibles. Madrid: El Mundo, 1999.

CASTEL, R. La metamorfosis de la cuestión social: una crónica del salariado. Madrid: Paidós, 1997.

CASTEL, R. Encuadre de la exclusión. In: KARSZ, S. (Coord.). La exclusión: bordeando sus fronteras: definiciones y matices. Barcelona: Gedisa, 2004. p. 55-86.

CORVALÁN, G. Modo de vida de los mineros del carbón. Golfo de Arauco. In: CORVALÁN, G. Mundo minero: Chile, siglos XIX y XX. Santiago: Universidad de Santiago de Chile, 1992. p. 125-150.

DE DINECHIN, P. Identidad y reconversión en las ciudades carboníferas de Lota y Coronel-Chile. Santiago: Fundación Cepas, 2001.

DÉOTTE, J. Catástrofe y olvido: las ruinas, Europa y el Museo. Santiago: Cuarto Propio. 1998.

DI MÉO, G.; BULEON, P. L'espace social: lecture géographique des sociétés. Paris: Armand Colin, 2005.

ECKERT, C. Memória e trabalho: etnografia da duração de uma comunidade de mineiros de carvão (La Grand-Combe, Franca). Curitiba: Appris, 2012.

GARCÉS, E. Las ciudades del salitre. Santiago: Editorial Orígenes, 1999.

GARCÉS, E. Las ciudades del cobre. Santiago: Ediciones Universidad Católica de Chile, Facultad de Arquitectura, Diseño y Estudios Urbanos, 2007.

GORZ, A. Metamorfosis del trabajo: búsqueda del sentido: crítica de la razón económica. Madrid: Editorial Sistema, 1995. 
HELLER, A. Sociología de la vida cotidiana. Barcelona: Península, 2002.

LE BRETON, D. Antropología del dolor. Barcelona: Seix Barral, 1999.

LÉVI STRAUSS, C. Tristes trópicos. Barcelona: Paidós, 2006.

MANNS, P. Cantología. Santiago: Catalonia, 2005.

MEDINA, P. La espera como forma alienada del sufrimiento humano. La Historia interrumpida de un pueblo minero. In: BILBAO, A.; MORLANS, I. (Ed.). Duelo, pérdida y separación: figuras del sufrimiento humano. Valparaíso: Ediciones Universitarias de Valparaíso, 2010. p. 117-128.

RIVAS, G. Prólogo. In: VEGA, P. Once días bajo tierra. Coronel: Imprenta San José, 2000.

ROCHA, A. L. C. da; ECKERT, C. Etnografia da duração nas cidades em suas consolidações temporais. Política \& Trabalho: Revista de Ciências Sociais, n. 34 , p. 107-126, abr. 2011.

RODRÍGUEZ, J. De la ciudad del trabajo a la ciudad del vacío: el lugar del sufrimiento. In: BILBAO, A.; MORLANS, I. (Ed.). Duelo, pérdida y separación: figuras del sufrimiento humano. Valparaíso: Ediciones Universitarias de Valparaíso, 2010. p. 91-106.

RODRÍGUEZ, J; MIRANDA, P. Tiempo industrial y tiempos sociales en María Elena, la última ciudad del salitre. Chungara: Revista de Antropología Chilena, v. 40, n. 1, p. 81-97, 2008.

RODRÍGUEZ, J; MIRANDA, P. María Elena: el fin de una experiencia urbana. Un estudio de caso en el desierto de Atacama, Chile. Eure, Santiago, v. 35, n. 105, p. 113-136, agosto 2009.

SARAMAGO, J. La caverna. Madrid: Santillana, 2008.

Recebido em: 30/12/2013

Aprovado em: 18/07/2014

Horizontes Antropológicos, Porto Alegre, ano 20, n. 42, p. 237-264, jul./dez. 2014 